to return again to the back, should it be necessary, which, however, it seldom is.

There is another form of acute thoracic inflammation in which blisters of a smaller size are extremely useful ; the local inflammations which often supervene in a tuberculised lung, around a cavern, or softened tubercles. If the patient in such a case is bled from the arm, or even leeches are applied to any extent, his strength is diminished by the loss of the vital fluid, and his few remaining days on earth proportionately diminished. One or two moderate-sized blisters over the region affected will generally suffice to subdue the inflammation, and that without much weakening the unfortunate patient, and thus precipitating his end.

I may resume the opinions which I have thus briefly expressed in the following manner :-

First. Both in non-inflammatory and in inflammatory diseases blisters do not give rise to as much general excitement as is generally supposed. Secondly. In the treatment of acute inflammatory diseases, especially those of the organs contained in the thoracic cavity, large blisters may be applied with perfect safety and great benefit, and are even more useful than in the chronic stages of those diseases. Thirdly. Their use is attended with but little pain, and never increases the inflammation, however near to it the blister may be applied. These assertions, as also those which $I$ have made with respect to the influence of blisters over the urinary system, will be found to hold good in the very great majority of cases, but certainly not in all. No rule is without an exception, especially in therapeutics, and some few cases may present themselves in which counter-irritation may produce great general irritation, and perhaps do harm. I am, however, convinced that such cases are excessivety rare. I must, also, in justice, state that although in severe acute thoracic disease the pain and annoyance of a large blister is but little felt, during the convalescence the patient often suffers considerable inconvenience from it. This, however, in my eyes, is but a trifling objection to the use of so powerful and so efficacious a therapeutic agent.

Cambridge-square, Hyde-park, August, 1844.

\section{ON THE NATURE OF NEURALGIA AND TIC} DOULOUREUX.

By Edward Binns, M.D., Hounslow.

In The LaNCET of the 17th of August, 1844, there is a letter from Dr. Skae, of Edinburgh, claiming the anatomical theory of pain in neuralgia. This gentleman refers to a paper, by himself, in a northern periodical for 1840, in support of his claim. Other practitioners have also claimed this theory, among whom, if I understand Dr. Skae rightly, are Drs. Black and Wallis. Dr. S. says, "Dr. Black proceeds on the principle that the affected nerves, being contained in rigid canals, must be subjected to injurious pressure whenever their accompanying vessels are unusually distended with blood." And, again, according to Dr. Wallis, " upon this pressure depends the neuralgic paroxysm." (LANCET, August 17th, 1844.)

Now, I do not lay claim to this "discovery," or "theory," but I will relate what occurred to myself in 1828, when I was examined for my degree in Edinburgh. About the conclusion of the severe examination by each professor of the faculty individually, an examination that I am quite certain he who has once undergone would never voluntarily undergo a second time, for, independent of the knowledge required in botany, anatomy, medicine, materia medica, therapeutics, \&c., the questions and responses were then put and made in Latin, and when I had begun to congratulate myself that all was going on smoothly, Dr. Monro, professor of anatomy, still alive, commenced his inquisition. Among many dissimilar questions, one of which was, which were perforations and which were not in the diaphragm, he asked me to define neuralgia. I did so in the usual way. The remedies for the alleviation or cure of the disease were next required, and, after enumerating opium, arsenic, quinine (then a novelty), and what not, I added cold. This was very nearly fatal to me. The professor actually groaned and turned himself abruptly on the chair, resting his face on his right hand, as if the idea of my remedy had given him tic douloureux. As may be conceived, I was not a little alarmed. I had been under the fire of the faculty for more than an hour and a half, and was faint, it being an extremely warm day in June, nevertheless I timidly repeated that cold was a remedy. The professor seemed roused by the repetition, and asked me the question a third time. I replied again in the affirmative. He then inquired an explanation of the modus operandi? I immediately asked leave to give my reasons in English ; to this request he kindly consented. I then said, that the object in applying cold was to repress or moderate congestion (upon this doctrine I do now insist, as I am only detailing what occurred, and $\mathrm{Dr}$. Monro may probably remember the circumstance), because I imagined there was congestion of the bloodvessels surrounding the neurilema, which caused pressure on the nerve in its adit and exit from the osseous canal or, in other words, I gave the same explanation, or theory of the pain, claimed by Drs. Black, Wallis, and Skae, which I am ready to believe is original to all, since it is so obvious in most cases. I believe this theory of the pain in neuralgia is founded on sound pathological principles. I have known the citrate of iron aggravate the pain most sensibly, while venesection, when all other remedies have failed, has produced decided good effects. One case I have met with recently, -it was that of a joiner and cabinet-maker, of the name of Leslie, who lives in my immediate vicinity. He had been suffering for many years under neuralgia in its most aggravated form ; none of the usual remedies afforded any relief. He was bled at Christmas, ad deliquium, since which period his attacks have been less frequent and less severe. After venesection he was treated with arsenic (Fowler's solution) and citrate of iron. He is now, comparatively speaking, free from neuralgic attacks, but the disease, I regret to say, is not radically extirpated. August, 1844 .

\section{MIDWIVES' MIDWIFERY.}

By Robert Barnes, M.B., M.R.C.S.

I FORWARD to THE LANCET the following specimen of midwives' midwifery, not that I imagine such to be of rare occurrence, or hitherto unnoticed, but because that it is but discharging a duty to society to set on record proofs of the lamentable extent to which life and limb are brought into jeopardy by the culpable rashness of ignorant persons. It will be conceded that this duty is the more imperative at this particular time, when it is in contemplation to abandon a large proportion of the population of these realms into the hands of charlatans and impostors.

I was called up at a quarter past eleven, p.m., yesterday to go to a midwife engaged at a labour in the immediate neighbourhood of my residence. I found the patient tossing about on the floor in a state of great excitement, afraid that all was not going on well, and calling aloud for the use of instruments, having been in labour since early in the morning, although the midwife had "worked like a horse." On a rapid examination I found the head low down in the pelvis; there being time, I consequently lifted the patient on to the bed, in which proceeding I was resolutely opposed by the midwife, who loudly exclaimed against any interference with " her case." She boasted that the "hand had been down, and that she had turned the child." On the strength of this feat, and of having been twenty-six years a "merical woman," she was determined not to yield, although the friends had sent for me. I, however, insisted on making a more accurate examination. I then found the head on the perineum, a large mass of the umbilical cord protruding, and the expelling pains strong; there was, as might be expected, no pulsation in the cord. Having ascertained the state of affairs, I asked the "midwife" her opinion as to the nature of the case. "The hand had come down, and she had turned the child," was the re- 
ply! I took leave to accuse her of ignorance, and pronounced the child to be dead, in all probability through improper treatment. As the woman stuck resolutely to her post, I left the bedside to remonstrate with the husband, and to insist upon the midwife's leaving, and to send for another practitioner to support me, and witness the proceedings. The midwife hereupon named one of Sir J. Graluam's protégés, an unqualified practitioner, as a proper person to be called in. Par nobile fratrum! (the medical woman and the impostor be it understood). In the mean time the child was born, and the midwife, as is the wont of the sisterhood, lost no time in hauling away at the placenta, which, by way of enhancing her own cleverness, she declared to be a "fixture." It, however, soon came away, though she worked as hard as she could to make it a difficult matter. The job done, she fell down on her knces and thanked the Lord for his mercy, not forgetting to extol her own share of the merit, that she "had brought her patient through." She unconcernedly enough overlooked the fact that there were twopatients in the case instead of one; the child was of no importance; and besides she said "the children were always born dead when the cord came down." This reminds one of Dr. Blundell's midwife (v. Lect. in LANCET) who "always broke the child's leos in a breech-presentation."

The child was full-grown; the face was very livid; the scrotum swollen and red; the cuticle not separable, nor the bones of the head remarkably loose. I considered the child might have been dead nine or ten hours. I have seen the patient this morning; she feels assured that the child was alive at twelve, p.m. The miduife broke the membranesateleven, p.m. The patient has passed a bad night, and complains of great pain in the abdomen, which is hardly to be wondered at. Were I to turn to the records of my experience while house-surgeon to the Queen Adelaide's Lying-in Hospital, I could easily cite other cases as appalling as the preceding. This one will serve to show the fearful dangers to which poor women are exposed in the critical moment of parturition, when left to the tender mercies of midwives and " their consulting surgeons," to wit, such as the unqualified practitioner alluded to.

And now, without stopping to comment upon the foregoing case, to prove the homicidal ignorance of the midwife, to show that the child might have been saved, or that the woman's life was perilled, all this being a work of supererogation, I would inquire what is the remedy for so fearful a state of things? Are the lives of the labouring classes to be utterly despised? Is there to be no care for the prevention of manslaughter? Legislators would do well to pause ere, by passing Sir James Graham's Bill, they give such a damning proof that laws are made for the rich and not for the poor.

It may be argued that medical practitioners could not possibly take charge of all the midwifery of the country. There is no proof of that; but, in God's name, if women must be employed, let them have an obstetric education, as in France; let our poor countrywomen have some guarantee that they fall into the hands of respectable and competent persons; let us be assured that these persons shall know the difference between the human hand, and a handful of umbilical cord.

In the meantime, and while continuing to pray that our law-givers may be "endued with grace, wisdom, and understanding," upon this point, the medical profession, whose highest honour it has ever been to stand forward as the natural protectors of the poor, should exert themselves to diminish the evil. I conceive this may be done to a great extent by the establishment and extension of lying-in charities; and I firmly believe that the ladies of the middling and upper classes would cheerfully co-operate in providing their poorer neighbours with that succour which they themselves enjoy.

One word more in reference to the so-called Medical Reform Bill. Sir James Graham would place no penalties upon the practice of medicine by unqualified persons; he would only provide against their holding any public appointments. Of course, he would not be so ungallant as to make an exception to the prejudice of the " medical ladies." They will be preserved, of course, in the undisputed right of practising in the most important class of cases in which the art of medicine is called upon to administer relief to suffering humanity. It need not be asked whother the post of parish-midwife will be considered a public appointment. Sir James Graham and the monopolists by whom he is earwigged, will doubtless determine that any woman is competent to practise midwifery, as any rogue is to practise medicine. Surely, then, if impurlence enough and knavery enough are to be held as sufficient qualifications for the practice of medicine, the motto of Sir James Graham and his Bill must be :-

"Tis foll Where ignorance is bliss

Bulmer Huuse, Notting Hill, Aug. 14, 1814.

\section{THE HYDROSTATIC BED}

\section{To the Editor of THE LANCET.}

SIR,-Although the value of the hydrostatic bed is admitted by all who have experienced or witnessed its advantages in cases where undisturbed sleep is an essential element in the curative treatment, yet this value is not generally known. Permit me, through your valuable Journal, to state what I conceive to be the principal reasons of this. I am prompted to this communication by the desire that the benefit which one who is dear to me is now deriving from the floating bed should be more extensively afforded, and by havin discovered a great defect in the particular bed which was sent for this person's use, and which being common to all the beds of the same maker, must have been the source of much disappointment, and prohably worse evil.

Such defects I consider to be one reason of the bed not being in more general use. The error in the construction of that which I have just mentioned is there being no opening left for the escape of the air that collects on the top of the water, so that when the patient first lay down upon it the air contained within the Macintosh cloth caused this to bulge on either side of the body, and the bed thus really was more of an air bed, supporting the incumbent weight by the tension of the cloth as a hammock does, than a water bed. A hole made by a gimblet near the top of the case would rectify this.

Another reason for the slow progress to due estimation, as respects this bed, is that it is not a patent invention. The inventor was, no doubt, actuated by the best motives in making a present of it to the public; but I think his object would have been better attained-his object of making it as useful as possible to suffering humanityhad he retained the right of constructing it in his own hands. Such blunders as that which $I$ have just particularised would not have been committed, and discredit thus thrown upon his invention. I believe that Davy regretted, on this account, that he similarly presented his safety-lamp to the public. Instead of the price being greater it would have been much less, even allowing that the inventor (which probably would not have been the case) had participated in the profit arising from the sale. More beds would have been sold, and, consequently, a less profit would have sufficed. In regretting that he did not take out a patent, far be it from me to recommend the vile practices of certinin patentees of medical inventions, - worthless and expensive trash, eternally thrust on the public by all the diversified arts of puffing, and great benevolence pretended by the inventors in order to fill the pocket with more decency. I am well aware that the apprehension of being classed with men of this description is a strong reason for not patenting such inventions. For these men cunningly use all the arguments which I have adduced in the hope of saving themselves from welldeserved contempt. Yet surely the author of the "Elements of Physics" need not have dreaded such a want of discrimination in the public.

A third reason is the little care taken by the profession to recommend this novelty, - to supply the place of a puffing and advertising patentee. But the truth is that many of the profession have yet to become acquainted with the use and merits of the hydrostatic bed. All that can be effected by it (in the opinion of some) is the prevention or cure of ulceration and sloughing from pressure. Right in this application of the bed, they are 